\title{
Game Analysis between Banks and B2B Platforms in Agricultural Electronic Order Financing
}

\author{
Xiaoxu Chen ${ }^{1} \&$ Peng $\mathrm{Xu}^{2,3}$ \\ ${ }^{1}$ School of Economic and Management, Shanxi University, Taiyuan 030006, China \\ ${ }^{2}$ School of Business, Southwest University of Political Science and Law, Chongqing 401120, China \\ ${ }^{3}$ John Molson School of Business Concordia University, Montreal H3G 1M8, Canada \\ Correspondence: Peng Xu, School of Business, Southwest University of Political Science and Law, Yubei District, \\ Chongqing 401120, China. E-mail: xupengswul@163.com
}

Received: December 25, 2018

Accepted: January 20, 2019

Online Published: January 21, 2019

doi:10.5430/bmr.v8n1p11

URL: https://doi.org/10.5430/bmr.v8n1p11

\begin{abstract}
In recent years, agricultural electronic order financing has developed rapidly, and cooperation between banks and B2B platforms has become the main mode of operation. In the process of cooperation, there are moral hazards caused by information concealment. On the basis of analyzing the business characteristics and the behavior strategies of both sides, this paper discusses the cooperation mechanism between the two sides by using the game analysis method. The results show that the strategy choice of the banks and the B2B platforms is not only affected by the credit of financing customers, but also by the concealment cost and the concealment income. When the concealment cost is less than the concealment income, the profit distribution ratio and the default compensation ratio can be the key factors of affecting the strategy choice of the B2B platforms and the banks. When the concealment cost is greater than the concealment benefit, the change value of the income distribution caused by the different strategies has an important impact on the strategy choice of the banks.
\end{abstract}

Keywords: agricultural products, electronic orders, B2B platform, bank

\section{Introduction}

With the rapid development and maturity of internet technology, the e-commerce business of agricultural products is developing rapidly. Many small and medium-sized agricultural enterprises and core enterprises in the supply chain trade on the B2B platform. Upstream farmers, cooperatives and small and medium-sized enterprises have a large number of electronic orders from the core enterprises. However, the upstream suppliers lack enough funds to purchase raw material for production. They are unable to produce normally, resulting in the failure to perform the contract on time. Therefore, it is an urgent task to solve the shortage of funds. The agricultural order financing provides an effective way to alleviate the financing dilemma. Because of the huge advantages of business modes, it has attracted wide attention. Kaplan and Sawhney studied the path and method of an electronic center introduced into the order financing (Kaplan S, Sawhney M., 2000). Heng analyzed the impact of the e-commerce on the financial system, and gave the concrete manifestation of the interaction between the two sides from three aspects (Heng M. S. H., 2001). Gu Min studied the specific modes of the electronic order financing according to its characteristics (Guo J.E., Shi J.Z., Wang Z. X., 2014). Li analyzed the difference of risk elements between online and offline order financing in detail, and put forward the precautions against the financial risk of the online order financing (Gu M., 2015). Guo et al. studied risk factors and management countermeasures of the online supply chain finance (Li Y.Q., 2015). Shi et al. discussed the incentive contract design between a bank and a B2B e-commerce platform from two aspects of joint credit and entrusted credit (Shi J. Z, Guo J. E., 2015) (Shi J. Z., 2015). Wang et al. studied the evolution process of the principal-agent problem between the bank and the B2B platform, and analyzed the incentive contract design considering fairness preference factors (Wang K. F., Shi K. R., 2016) (Wang K. F, Shi K. R., 2017). $\mathrm{Xu}$ studied the construction of a risk index evaluation system of the online agricultural supply chain finance, and evaluated risks in the business applying for analytic hierarchy process and structural equation model (Xu P., 2016).

However, compared with the traditional order financing business, the significant feature of the agricultural electronic order financing is the participation of the B2B platform, and in the process of business development, the mainstream mode of cooperation between the bank and the B2B platform is gradually formed because of the respective 
advantages of both sides (Guo J.E., Shi J.Z., Wang Z. X., 2014). The bank has scientific risk assessment mechanism, risk prevention mechanism, strong financial strength et al. The B2B platform is outstanding in data collection, data processing, big data application, information sharing et al. With the development of science and technology, the two sides have made use of their respective advantages to cooperate to complete the agricultural electronic order financing, which is in line with the interests of both sides. So in recent years, the practical business based on the cooperation between the two sides has developed rapidly (Shi J. Z, Guo J. E., 2015).

To the best of our knowledge, there is little literature on game analysis between the bank and the B2B platform. We fail to find a paper on strategy choice of the bank and the B2B platform during the course of their cooperation, this paper may be the first to discuss the question in agriculture electronic order financing, and to give the equilibrium strategies of both sides.

\section{Definition and Operation Process of Agricultural Electronic Order Financing}

The agricultural electronic order financing is a new financing mode derived from the application of the order financing in agricultural supply chain, which is based on real trade with core enterprises and the help of internet technology. It aims to make up for the weak points of capital in the agricultural supply chain. This mode is different from the traditional order financing. The prominent feature of this mode is the participation of the B2B platform. The B2B platform plays an important role in business, on the one hand, it gathers a large number of financing customers by means of platform members, on the other hand, the B2B platform collects highly the trading information of trading members, and uses big data technology to analyze and sort out the useful information. These characteristics provide a realistic basis for banks to seek cooperation. In addition, the agricultural electronic order financing can be divided into two operation modes, one is "downstream mode" and the other is "upstream mode". The downstream mode refers to the operation mode based on the orders formed by core enterprises and downstream wholesalers or retailers trading on the $\mathrm{B} 2 \mathrm{~B}$ platform, which solves the problem of the insufficient purchase funds of the wholesalers or the retailers; the upstream mode refers to the operational financing mode occurring between core enterprises and upstream suppliers with the orders formed on the B2B platform, and the upstream mode aims to solve the problem of the insufficient production funds for upstream supplies. As far as the agricultural products supply chain is concerned, many farmers, cooperatives and small and medium-sized enterprises often have orders but lack funds to purchase raw materials for production activity. As a result, the products cannot be completed on time, or the quality of products is not high, which results in the delay or stagnation of downstream production activity, and affects the effective operation of the whole supply chain. In other words, the agricultural electronic order pledge financing, especially upstream order financing, is of great significance to break down the weak links of farmers, cooperatives and other small and medium-sized enterprises. It is necessary and urgent to promote the healthy and efficient operation and enhance the effectiveness of the business.

The operation process of the agricultural electronic order financing is as follows: In the agricultural supply chain, small and medium-sized enterprises trade with core enterprises on the third-party B2B platform, forming the electronic orders, and then apply for loan from the bank through the order financing. The bank entrusts the B2B platform to evaluate electronic credit (transaction records, registration time, and credit rating) and operational conditions of financing customers (high credit and low credit), and then provide the evaluation report to the bank. There are two types of the reports: the true report and the false report. The true report is that the B2B platform truthfully recommends customers to the bank based on the results of the investigation, and does not conceal their types; on the contrary, the false report refers to the recommendation by the B2B platform through artificial operation, accounting treatment, report whitewash, etc., the real situation of financing customers is concealed and deceived. After receiving the recommendation report from the $\mathrm{B} 2 \mathrm{~B}$ platform, the bank has two kinds of strategy choices for the recommendation report: review or no review. After getting the loan, financing customers will carry out production activities, and then provide products to the core enterprises on schedule. The core enterprises will put money into designated accounts. After deducting principal and interest, the bank will release the pledge order and deposit, the business is completed.

\section{Model Assumptions and Game Analysis}

\subsection{Model Assumptions}

(1)In the agricultural product supply chain, the upstream financing customers (including farmers, farmers cooperatives, etc.) trade with core enterprises through the B2B platform, and then get their orders, but they have insufficient funds to purchase enough raw materials for production activity.

(2)The upstream financing customers apply for loans from banks by regarding electronic orders formed with core 
enterprises as guarantee. The bank entrusts the B2B platform to evaluate the status of the financing customers based on their financial information, electronic credit information, authenticity of electronic orders and quality of electronic orders. The B2B platform may conceal these information and cause moral hazard problems during the course of recommending financing customers.

(3)There are two types of financing customers: high credit and low credit, the two types are defined as follows: the customers that fulfill the repayment on schedule are high credit customers; otherwise they are low credit customers.

(4)There are enough upstream financing customers during the credit period, so there is no surplus of the credit line $I$. The cash deposit of the financing customers is $L$, so the loan value ratio is $k=\frac{I}{I+L}$.

(5)For the benefits from the business, the allocation ratios of the bank and the B2B platform are as follows: it is $s_{1}:\left(1-s_{1}\right)$ when banks choose the non-review strategy; it is $s_{2}:\left(1-s_{2}\right)$ when banks choose the review strategy. The income allocation ratios are different in the two cases, and the income allocation ratio at the review is greater than that at the non-review (Shi J. Z., 2015).

(6)If the financing customers defaults, the bank will receive partial compensation, the compensation ratio is $\phi$, the compensation is from the government's support fund for farmers, the core enterprise's support fund, the insurance company's compensation, or the funds pool composed of two or three parties (Xu P., 2016).

(7)Both participants have two strategic choices. The strategies of the B2B platform are concealment and non-concealment, and the two strategies of the bank about financing customers recommended by the B2B platform are review and no review. When the bank chooses to review, the information concealed by the B2B platform will be found. Without review, the banks will make its decision based on the recommendation information from the B2B platform.

(8)The cost of the bank review is $C_{b}$, the cost of the B2B platform concealment is $C_{p}$, but the B2B platform can benefits from the concealment of the low-credit enterprises, the amount is $H$.

(9)In the course of the game, all information is open and transparent, which includes all explicit parameters (order authenticity, order amount, financing amount, loan value ratio, interest rate, margin, income distribution rate, etc.) and invisible parameters (the bank's compensation ratio, investigation cost, concealment cost, concealment income etc.), so that the benefits of the banks and the B2B platform under various strategies can be easily made.

\subsection{Game Analysis}

In the process of the game, the bank's strategy is no review or review, the B2B platform's strategy is no concealment or concealment. There are four situations of the game, namely (no review, no concealment), (no review, concealment), (review, concealment) and (review, no concealment). Combining with the assumptions above, the benefits corresponding to the four situations in two types of enterprises (high credit and low credit) are shown in Table 1.

Table 1. The game results of the banks and the B2B platform

\begin{tabular}{|c|c|c|c|c|}
\hline \multirow{3}{*}{ Game strategies } & \multicolumn{4}{|l|}{ B2B platform } \\
\hline & \multicolumn{2}{|c|}{ Low credit customer } & \multicolumn{2}{|c|}{ High credit customer } \\
\hline & no concealment & concealment & no concealment & concealment \\
\hline \multirow[t]{2}{*}{ no review } & 0,0 & $\frac{I \phi}{\kappa}-L, H-C_{p}$ & $I r s_{1}, \operatorname{Ir}\left(1-s_{1}\right)$ & $0,-C_{p}$ \\
\hline & $-C_{b}, 0$ & $-C_{b}, H-C_{p}$ & $I r s_{2}-C_{b}, I r\left(1-s_{2}\right)$, & $I r s_{2}-C_{b}, I r\left(1-s_{2}\right)-C_{b}$, \\
\hline
\end{tabular}

From the game results in Table 1, we find that different types of financing customers lead to different equilibrium results. For low credit customers, regardless of what the bank's strategy choice is, the strategy choice of the B2B platform depends on the difference between the concealment cost and the concealment income. If the concealment cost is greater than the concealment income, the best strategy of the B2B platform is no concealment, otherwise it is to conceal. For high-credit enterprises, the dominant strategy of the B2B platform is not to conceal regardless of whether the bank's strategy is not to review or review. From these two aspects, we can discuss and analyze the game activities. 
When $H>C_{p}$, that is, the concealment income is greater than the concealment cost. Under this situation, for low credit enterprises, the better choice of the B2B platform is concealment regardless of the bank's choice, while for high-credit enterprises, the dominant strategy of the B2B platform is not to conceal. Thus, the game matrix of both sides can be simplified as shown in Table 2.

Table 2. The game results of the bank and the B2B platform under $H>C_{p}$

\begin{tabular}{llll}
\hline \multirow{2}{*}{ Game strategies } & \multicolumn{2}{l}{ B2B platform } & High credit customer \\
\cline { 2 - 3 } & Low credit customer & no concealment \\
\cline { 2 - 3 } & no review & $\frac{I \phi}{\kappa}-I, H-C_{p}$ & $\operatorname{Ir} s_{1}, \operatorname{Ir}\left(1-s_{1}\right)$ \\
\multirow{2}{*}{ Bank } & review & $-C_{b}, H-C_{p}$ & $\operatorname{Irs}_{2}-C_{b}, \operatorname{Ir}\left(1-s_{2}\right)$ \\
&
\end{tabular}

Proposition 1. When $H>C_{p}$ and $s_{i} \leq 1-\frac{H-C_{p}}{I r}(i=1,2)$, the choice of the B2B platform is high credit customer and no concealment.

When $H>C_{p}$, it means the concealment income obtained by the B2B platform is greater than the concealment cost. Under this situation, the strategic choice of the B2B platform is as follows: If the financing customer is low-credit, its dominant strategy is concealment; if the financing customer is high-credit, its dominant strategy is no concealment, as shown in Table 2. For the two strategies, when $\operatorname{Ir}\left(1-s_{1}\right) \geq H-C_{p}$ and $\operatorname{Ir}\left(1-s_{2}\right) \geq H-C_{p}$, that is, $s_{i} \leq 1-\frac{H-C_{p}}{I r}$, the B2B platform will choose the high credit customer and not to conceal, obviously, it is better for the bank.

Proposition 2. When $H>C_{p}$ and $\phi>\left(r s_{1}+1\right) \kappa$, the concealment strategy of the B2B platform will not affect the expected benefits of the bank.

When $H>C_{p}$, if the expected benefits of the bank are not affected by the concealment strategy of the B2B platform, the following conditions should be met $\frac{I \phi}{\kappa}-I \geq I r s_{1}>0$, that is, $\phi>\left(r s_{1}+1\right) \kappa$. According to $\frac{I \phi}{\kappa}-I \geq 0 \geq-C_{b}$, the strategy choice of the bank is not to review.

Table 3. The game results of the bank and the B2B platform under $H \leq C_{p}$

\begin{tabular}{llll}
\hline \multirow{2}{*}{ Game strategies } & \multicolumn{2}{l}{ B2B platform } \\
\cline { 2 - 3 } & Low credit customer & High credit customer \\
\cline { 2 - 3 } & no review & 0,0 & no concealment \\
\hline \multirow{2}{*}{ Bank } & review & $-C_{b}, 0$ & $\operatorname{Ir} s_{1}, \operatorname{Ir}\left(1-s_{1}\right)$ \\
& & $\operatorname{Irs}_{2}-C_{b}, \operatorname{Ir}\left(1-s_{2}\right)$
\end{tabular}

Proposition 3. When $H<C_{p}$, the bank's strategy choice depended on the income distribution rate, the investigation cost and the loan income.

When $H<C_{p}$, the concealment income of the B2B platform is less than its concealment cost. The game results of both sides are shown in Table 3. Obviously, whether it is a low-credit customer or a high-credit customer, the strategy choice of the $\mathrm{B} 2 \mathrm{~B}$ platform is no concealment, in addition, $\operatorname{Ir}\left(1-s_{1}\right) \geq 0, \operatorname{Ir}\left(1-s_{2}\right) \geq 0$, thus, the choice of a 
high-credit customer and no concealment is the dominant strategy of the B2B platform. At this time, the strategy choice of the bank depends on the size relationship between $\operatorname{Irs}_{1}$ and $\operatorname{Irs}_{2}-C_{b}$. When $\operatorname{Irs}_{1}>\operatorname{Ir} s_{2}-C_{b}$, that is, $s_{2}-s_{1}<\frac{C_{b}}{I r}$, the strategy choice of the bank is no review; when $s_{2}-s_{1}>\frac{C_{b}}{I r}$, the strategy choice of the bank is review; when $s_{2}-s_{1}=\frac{C_{b}}{I r}$, the results keep the same whether the bank choose review strategy or no review strategy. It indicates that the strategy choice of the bank is based on the relationship between the increase of the income allocation rate brought by the review and the ratio of the review cost and the total loan income. The larger the difference $\left(s_{2}-s_{1}\right)$ is, the stronger the effect brought by the review, the stronger the motivation for the bank to choose the review.

\section{Conclusions}

The agricultural electronic order financing provides a feasible way for small and medium-sized enterprises in agricultural supply chain, especially upstream farmers, cooperatives and other economic organizations to solve the financing dilemma. Compared with the offline order financing mode, the significant difference of this mode is that the B2B platform participates in the business. The B2B platform has the advantages of big data collection, collation and analysis. Its participation provides technical guidance, comprehensive evaluation and other services for the development of the agricultural electronic order financing. The banks entrust their business which they are not good at to the B2B platform. The B2B platform uses its own advantages to comprehensively evaluate information of the financing customers, such as the electronic credit, registration time, transaction frequency, transaction quota and credit rating, and then provide the report to the bank for decision-making. In the process of cooperation, because of information asymmetry, there may be some problems such as information concealment in the process of evaluation. In view of this, it is of great significance to clarify the interaction and equilibrium results between them in order to maintain cooperation, to improve the assistance effectiveness and to ensure the healthy and sustainable development of the business. It is found that the strategy choice of the B2B platform are different for high-credit and low-credit financing customers. The relationship between concealment cost and concealment income will affect the strategy choice of the bank and the B2B platform. In a given situation, the strategy choice of the bank and the B2B platform can be affected by the allocation ratio of the income and the compensation ratio for breach of contract. The research results are of positive significance to overcome the problem of information asymmetry and maintain good cooperation between two sides.

\section{Acknowledgements}

This work was supported by the Shanxi Soft Science Project(no.2018041044-1), the National Social Science Foundation of China (no.16BGL002) and Shanxi Philosophy and Social Sciences Project of Universities(no.201803048).

\section{References}

Heng M. S. H., (2001). Implications of E-commerce for Banking and Finance. Netherlands: Vrije University, 1-14. https://doi.org/10.1007/0-306-47009-8_22

$\mathrm{Gu}$ M. (2015). Research on supply chain finance model of e-commerce enterprises. Journal of Commercial Economics, (18), 86-88. https://doi.org/10.3969/j.issn.1002-5863.2015.18.035

Guo J.E., Shi J.Z., Wang Z. X. (2014). Research on the mode evolution and risk management of the online supply chain finance based on the third-party B2B e-commerce platform. Journal of Business Economics, (1), 13-22. https://doi.org/10.15896/j.xjtuskxb.201504002

Kaplan S, Sawhney M. (2000). E-hubs: the new B2B market places. Harvard business review, 78(3), 97-106. https://doi.org/10.1210/jc.2009-0402

Li Y.Q. (2015). B2B platform online supply chain financial risk identification and prevention. Journal of Commercial Economics, (19), 89-90. https://doi.org/10.3969/j.issn.1002-5863.2015.18.036

Shi J. Z, Guo J. E. (2015). Study on the development and domestic practice of supply chain finance from the perspective of the internet. Journal of $X i^{\prime}$ an Jiaotong University: social sciences, 35(4), 10-16. https://doi.org/10.15896/j.xjtuskxb.201504002 
Shi J. Z. (2015). Study on the incentive contract between banks and B2B platforms based on the online supply chain finance. Journal of Management Science, 28(5), 79-92. https://doi.org/10.3969/j.issn.1672-0334.2015.05.007

Wang K. F, Shi K. R. (2017). Bank and online supply chain finance evolution analysis of principal agent in B2B platform. Financial theory and practice, (5), 73-77. https://doi.org/10.3969/j.issn.1003-4625.2017.05.013

Wang K. F., Shi K. R. (2016). Research on incentive mechanism of banks to B2B platform based on fairness preference. Financial theory and practice, (10), 62-66. https://doi.org/10.3969/j.issn.1003-4625.2016.10.012

Xu P. (2016). Risk prevention of online agricultural product supply chain finance. Journal of south China agricultural university: social sciences, 15(6), 93-103. https://doi.org/10.7671/j.issn.1672-0202.2016.06.010

Xu P. (2016). Risk prevention of online agricultural product supply chain finance based on factor analysis perspective. Journal of agro-forestry economics and management, 15(6), 674-680. https://doi.org/10.16195/j.cnki.cn36-1328/f.2016.06.083 